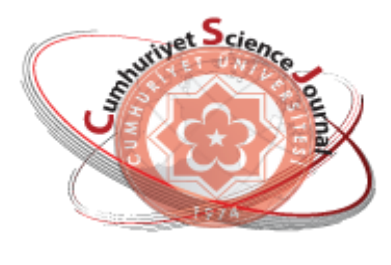

e-ISSN: $2587-246 X$

ISSN: $2587-2680$

\title{
The Effect of Semi-Circular Protrusions on Cylinder to Flow Structure
}

\author{
Ferhat KOCA ${ }^{1}$ (D), Adnan ÖZTÜRK ${ }^{2^{*}}$ \\ ${ }^{1}$ Sivas Cumhuriyet University Faculty of Technology, Department of Automotive Engineering \\ 58140 Campus, Sivas \\ 2 Sivas Cumhuriyet University Faculty of Engineering, Department of Mechanical Engineering \\ 58140 Campus, Sivas
}

\begin{abstract}
In this study; two dimensional, viscous, incompressible, fully developed and turbulent flows on the surface of the cylinder placed in a channel were analyzed using numerical methods. Momentum and continuity equations were solved numerically by ANSYS FLUENT program using finite volume method. The effect of the half cylinder $(\mathrm{d}=4.4 \mathrm{~mm})$ placed on the cylinder diameter (D) $44 \mathrm{~mm}$ in different positions $\left(0^{\circ}, 45^{\circ}, 90^{\circ}\right.$, $135^{\circ}$ and $180^{\circ}$ ) on the flow structure was examined. Streamlines and the turbulence kinetic energy contours were drawn for the Reynolds number $10^{4}$ value depending on cylinder diameter. As a result, downstream flow characteristics of cylinders having semi-circular protrusions placed in different positions were examined and drag force coefficients $\left(C_{D}\right)$ were obtained. It was concluded that the protrusion on the cylinder placed at different angles changed the flow structure and controlled the separation.
\end{abstract}

Keywords: Cylinder, CFD analysis, Drag force coefficient, Flow control

\section{Silindir Üzerindeki Yarı-Yuvarlak Çıkıntıların Akış Yapısı Üzerine Etkisi}

Özet. Bu çalışmada, bir kanala yerleştirilen silindir yüzeyi üzerinde iki boyutlu, viskoz, sıkıştırılamaz, gelişmiş ve türbülanslı akış, sayısal yöntemler kullanılarak analiz edilmiştir. Momentum ve süreklilik denklemleri ANSYS FLUENT programı ile sonlu hacimler yöntemi kullanılarak sayısal olarak çözülmüştür. Farklı konumlarda $\left(0^{\circ}, 45^{\circ}, 90^{\circ}, 135^{\circ}\right.$ ve $\left.180^{\circ}\right) 44 \mathrm{~mm}$ çapında (D) bir silindir üzerine yerleştirilmiş yarım silindirin $(\mathrm{d}=4.4 \mathrm{~mm})$ akış yapısına etkisi incelenmiştir. Akım çizgileri ve türbülans kinetik enerji konturları, silindir çapına bağlı olarak Reynolds sayısı 104 değeri için çizilmiştir. Sonuç olarak, farklı konumlara yerleştirilmiş yarı dairesel çıkıntılara sahip olan silindirlerin akım yönünde akış özellikleri incelenmiş, sürtünme direnç katsayıları (CD) elde edilmiştir. Farklı açılarda yerleştirilen silindir üzerindeki çıkıntının akış yapısını değiştirdiği ve ayrımı kontrol ettiği sonucuna varılmıştır.

Anahtar Kelimeler: Silindir, HAD analizi, Direnç katsayısı, Akış kontrolü

\section{INTRODUCTION}

The flows on the circular cylinder have attracted intensive interest from the past to the present for both experimental and numerical studies. These types of flow structures are encountered in many engineering applications such as wind-affected buildings, cooling towers and chimneys in thermal power plants, large silos, refineries, electronic circuits. Knowing of the flow structure and physics on the bodies, determining of the fluid forces acting on the bodies, the separation zones arising from the flow interaction between the body and its surroundings have great importance in the determination of the multi-vortex systems interacting with the body [1]. In addition, active and passive methods are developed in order to eliminate 
the effects of these vortices or to reduce them to a minimum level. Some of these methods are moving the surface through which the fluid flows, adding or drawing various gases at specific speeds, using other surfaces to prevent air flowing from the boundary surface, and cooling the surface through which the fluid flows. Active methods are used to control the energy level of the flow and the applications of these methods are expensive. In passive methods the flow structure is not directly changed, the desired form of the flow structure is obtained by changing the structural form of the body.

In the study of Canpolat and Sahin, a groove is cut into the surface of a circular cylinder and the effect of this groove on the flow structure is examined by particle imaging [2]. The groove, which was designed in a square shape, was patterned longitudinally on the surface of the cylinder with a diameter of $50 \mathrm{~mm}$, and in different positions (between $0^{\circ}$ and $150^{\circ}$ degrees) starting from the stagnation point. They observed that the critical position angle of the grooved structure is $80^{\circ}$ degrees, and stated the flow is controllable for positions less than $80^{\circ}$ degrees. In the study of Gundemir and Tastan, the effects of the longitudinalgroove roughness, which is placed on the outer surface of the pipe, on the drag force acting on the pipe were experimentally studied and compared with uniform sand roughness [3].

Oguz et al. studied the effect of braid wires having different thickness and permeability ratio wound around a circular cylinder with a diameter of $50 \mathrm{~mm}$ when the Reynolds number $\left(\operatorname{Re}_{\mathrm{D}}\right)$ is 5000 [4]. They determined four different permeability rates ranging between 0.5 and 0.8 with an increment of 0.1 , and thickness of the wires wrapped on the cylinder to be $1 \mathrm{~mm}, 2 \mathrm{~mm}, 3 \mathrm{~mm}$ and $4 \mathrm{~mm}$ in this study. Thus, the flow structure behind the cylinder was tried to be controlled by braid wires wound around the cylinder. Using the particle imaging technique, they observed that the turbulence kinetic energy (TKE) contours and Reynolds shear stress values for the cylinder with wires having thicknesses of $1 \mathrm{~mm}$ and $2 \mathrm{~mm}$ increased, but for the cylinder with wires having thicknesses of $3 \mathrm{~mm}$ and $4 \mathrm{~mm}$ decreased compared to the values of the plain cylinder. For the permeability ratio of $0.6 \mathrm{~mm}$ and the wire thickness of $4 \mathrm{~mm}$, TKE and Reynolds shear stress values are shown that the braid wires control the flow behind the cylinder. Considering the result of the frequency values, they stated that optimal control of the flow is provided when the permeability ratio is $0.6 \mathrm{~mm}$ and wire thickness is $4 \mathrm{~mm}$.

In the study of Akar and Kucuk, it is aimed to control flow structure downstream of the inner cylinder with different diameters by a surrounding outer cylinder that has 0.5 porosity [5]. The diameter of outer cylinder was chosen as $D_{0}=100 \mathrm{~mm}$. The perforation hole diameters of the cylinder were $d=10 \mathrm{~mm}$. The depth-averaged free stream velocity was $U=100 \mathrm{~m} / \mathrm{s}$ which corresponded to $\mathrm{Re}_{\mathrm{D}}=10000$ based on outer cylinder diameter. Flow characteristics downstream of the cylinder were investigated by using particle image velocimetry (PIV) technique. PIV experiments were performed at the mid-section of water $200 \mathrm{~mm}$. It has been observed that the perforated outer cylinder decreased vortex shedding downstream of the inner cylinder with different diameters. For high diameter ratios, $D_{i} / D_{o} \geq 0.7$ perforated outer cylinder lost its effect on the flow control.

Ranjith et al. studied the flow analysis on a circular cylinder having helical coatings using the HAD method [6]. They examined the effectiveness of helical coatings that suppress the vortex-induced vibration (VIV) of the helical cylinder at two different Reynolds numbers (100 and 28000) by providing three initial helical coatings around the circular cylinder. Static pressure, velocity magnitude, vorticity contours, drag $C_{D}$ coefficient and lift $C_{L}$ coefficient were obtained. They reported that the helical-coated cylinder has a higher coefficient of friction than the plain cylinder and the helical coatings can reduce VIV by about $99 \%$. 
Yeo and Jones studied the behavior of the flow around the surface using numerical methods in order to understand the interaction on the helical coated circular cylinder surfaces and the Karman vortex-induced vibrations [7]. They examined the flow around the yawed cylinder with various spiral patterns using threedimensional discrete vortex simulation (DES) at number of $\operatorname{Re}_{\mathrm{D}}=1.4 \times 10^{5}$ depending on the free flow rate and the cylinder diameter, D. As a result, they presented that the helical models strongly influence the flow structures around the cylinder and the development of the associated forces on the cylinder. They stated that suitable cylinder surfaces can reduce large-amplitude and low-frequency vibrations induced by the flow.

Lam et al. performed the Large Eddy Simulation (LES) to examine the three-dimensional properties of turbulent flow past cylinders having yaw angles from $0^{\circ}$ to $60^{\circ}$ at a Reynolds number of 3900 [8]. They examined the force coefficients and the relationship between the vortex frequency and the yaw angles for both wavy cylinders and circular cylinders. Differences in the vortex structure between the wavy cylinder and the circular cylinder were found to be significant when yaw angles are small. It is emphasized that the differences are insignificant at large angles and the critical angle value is stated to be $45^{\circ}$.

In this study, the effect of a single cemi-circular protrusion placed on a cylinder with a diameter of $44 \mathrm{~mm}$ in different positions on the flow structure has been examined for the $\operatorname{Re}_{\mathrm{D}}=10^{4}$. To the best of our knowledge, the effect of the channels placed along the length of the cylinder in the studies related to this subject was examined, but the effect of the small diameter half cylinder placed in different positions on the flow structure was firstly investigated in the present study.

\section{MATERIAL AND METHOD}

The cylinders to be analyzed were formed by adding semi-circular protrusions in different positions as seen in Figure 1. In the study, five different designs were formed using the $45^{\circ}$ increase between $0^{\circ}$ and $180^{\circ}$ in the counterclockwise direction and semi-circular protrusions placed on the horizontal axis. The schematic of the flow field is presented in Figure 2.

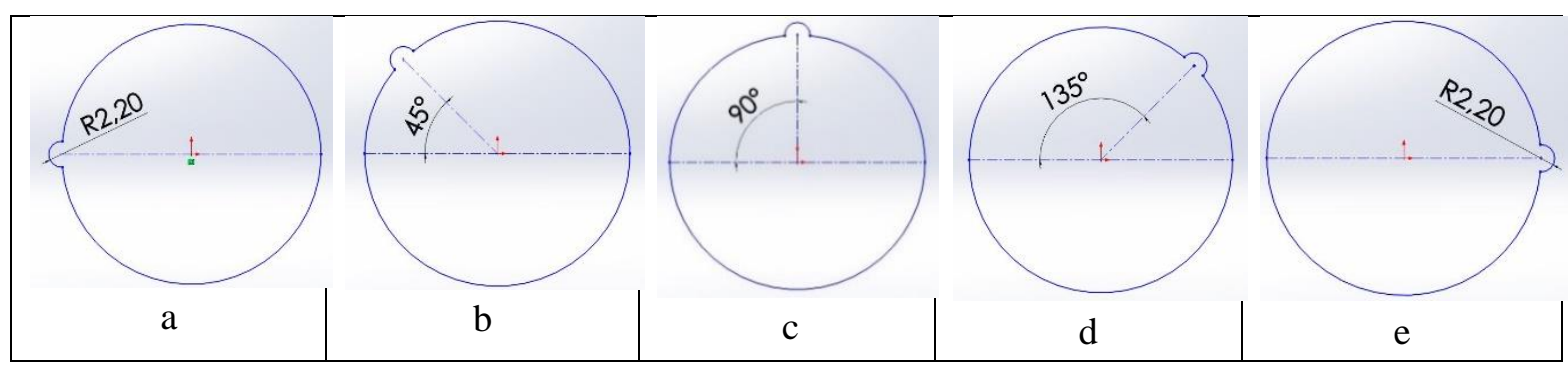

Figure 1. Positions of protrusions on the cylinder for a) $0^{\circ}$, b) $45^{\circ}$, c) $90^{\circ}$, d) $135^{\circ}$, e) $180^{\circ}$

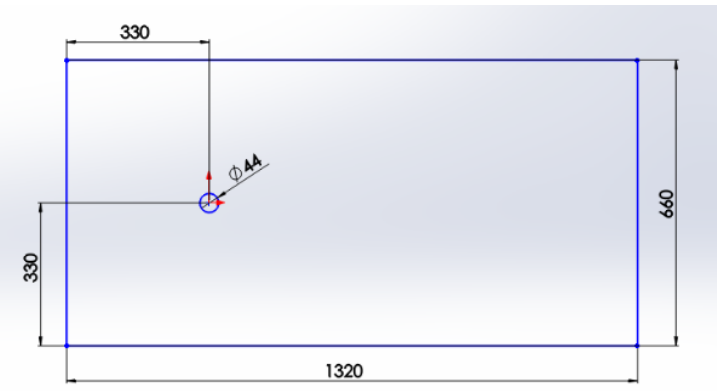

Figure 2. The schematic of the flow field (mm) 
The mesh structure of the flow field and mesh independence graph are presented in Figure 3. The edge sizing method was used to refine the mesh around the hole to obtain acceptable results. Accordingly, the circumference of the hole was divided into 100 equal elements, and the triangular mesh was used. The mesh consisting of 17415 mesh elements and 8999 nodes was produced and analyzed.
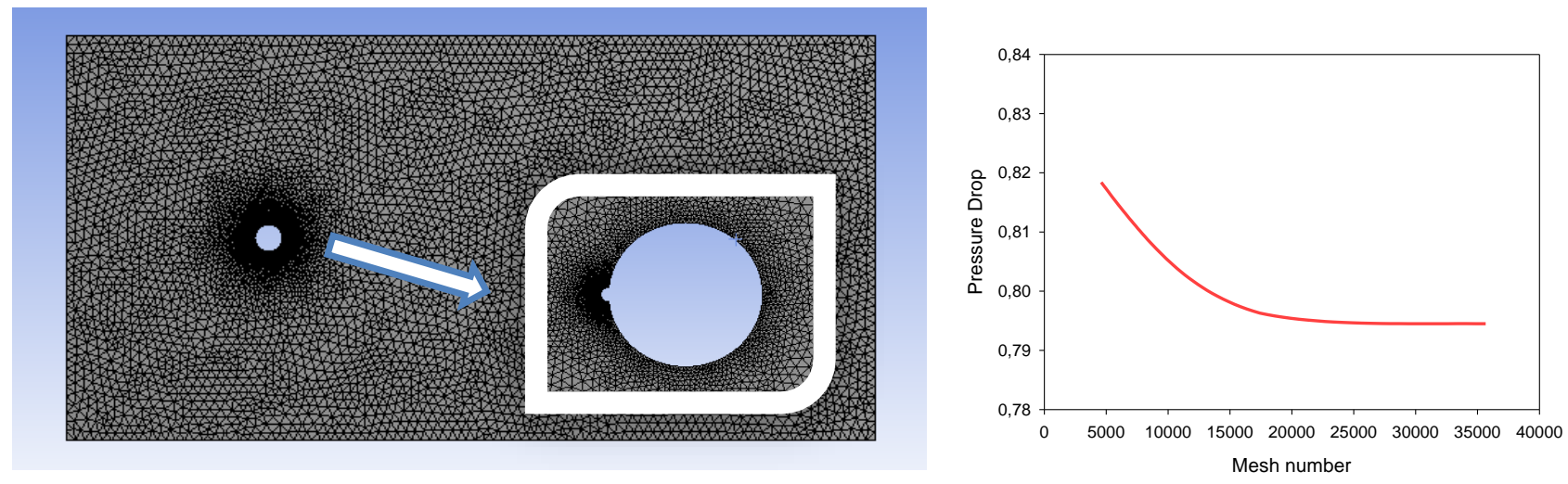

Figure 3. Mesh structure and independence

Figure 4 shows the boundary conditions of the flow fields. The velocity inlet and pressure outlet boundary conditions were used at the inlet and outlet of the flow channel. The side surfaces of the channel were defined as a wall where there is no fluid inlet and outlet with no-slip boundary condition. Also, in order to obtain forces acting on the surface of the cylinder, the surface of the cylinder was defined as a wall.

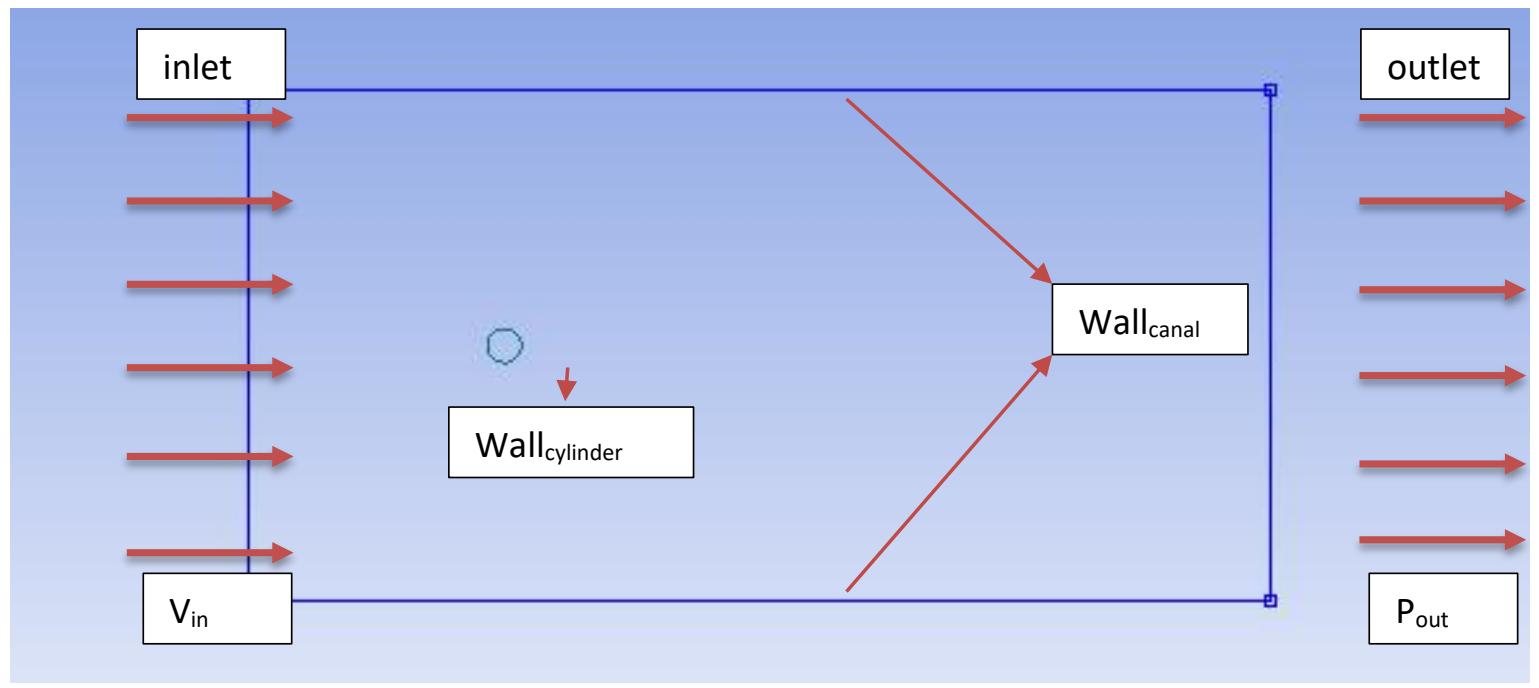

Figure 4. The boundary conditions of the flow fields

For 2D cartesian coordinate system, continuity, momentum, and energy equations were solved by using the Boussinesq approach and the conservation equations were defined as follows.

Continuity Equation:

$\frac{\partial u}{\partial x}+\frac{\partial v}{\partial y}+\frac{\partial w}{\partial z}=0$

Momentum Equation:

$u \frac{\partial u}{\partial x}+v \frac{\partial v}{\partial y}+w \frac{\partial w}{\partial z}=-\frac{1}{\rho} \frac{\partial P}{\partial x}+v\left(\frac{\partial^{2} u}{\partial x^{2}}+\frac{\partial^{2} v}{\partial y^{2}}+\frac{\partial^{2} w}{\partial y^{2}}\right)$ 
Energy Equation:

$u \frac{\partial T}{\partial x}+v \frac{\partial T}{\partial y}+w \frac{\partial T}{\partial z}=\alpha\left(\frac{\partial^{2} T}{\partial x^{2}}+\frac{\partial^{2} T}{\partial y^{2}}+\frac{\partial^{2} T}{\partial z^{2}}\right)$

The Eqs. (1-3) are arranged according to the following boundary conditions:

All the walls and the cylinder were modeled to be monolithic and adiabatic.

In the free current zone, $u=0.228 \mathrm{~m} / \mathrm{s}\left(\operatorname{Re}_{\mathrm{D}}=10^{4}\right.$ depending on the cylinder diameter $)$

$\partial T / \partial x=0$, on the side walls: $v=0$, upper and lower walls: $w=0$,

The dimensionless parameters used in this study as follows;

$R e_{D}=\frac{\rho u D}{\mu}$

where $\rho$ is fluid density, $u$ is free stream velocity, and $\mu$ is fluid viscosity.

Drag coefficient;

$C_{D}=\frac{F_{D}}{\frac{1}{2} \rho A u^{2}}$

where $F_{D}$ is the drag force on the cylinder created by the fluid, A is the area of the cylinder perpendicular to the flow direction.

Strouhal (St) Number:

$S t=\frac{f_{S} D}{u}$

here $f_{s}$ is the vortex frequency value.

This study was made under the following assumptions:

- Flow is 2D, time-independent and turbulent,

- The fluid used is incompressible $\left(\rho=998 \mathrm{~kg} / \mathrm{m}^{3}\right)$

- Aluminum is used as the boundary of the cylinder and the channel material,

- There is no heat transfer between layers.

- The fluid flows into the channel at a certain speed in the X-direction,

- The thermal properties of the fluid are constant,

- There is no heat generation in the fluid and at the boundaries.

\section{RESULTS AND DISCUSSIONS}

The properties to be obtained such as the distances ( $a, b, c, d)$ from the center of the cylinder and the locations $\left(\mathrm{F}_{1}, \mathrm{~F}_{2}\right)$ of the vortices to be compared in the results of analysis, the location of the streamlines in which the flow separation occurs (A), and the junction location (S) of the streamlines formed behind the cylinder are shown in Figure 5. The distances of the vortex centers to the center of the cylinder are shown in (a) and (b) on the horizontal axis, and in (c) and (d) on the vertical axis. It is investigated how the position of the vortices formed in the downstream region changes relative to the semi-circular protrusions placed on the cylinder. The $F_{1}$ and $F_{2}$ value shows the center position of the upper and lower vortex, respectively. These vortices are caused by the effect of the circular cylinder placed upstream. The saddle point $(S)$ indicates the location of the endpoint of the vortex's circulation zone. The distances between all these points as well as their position relative to the cylinder center are extremely important in order to change the vortex control mechanism to the desired form. The vortices must be kept under control to eliminate or minimize the negative effects caused by the resistance and oscillation movements on the cylinder. 


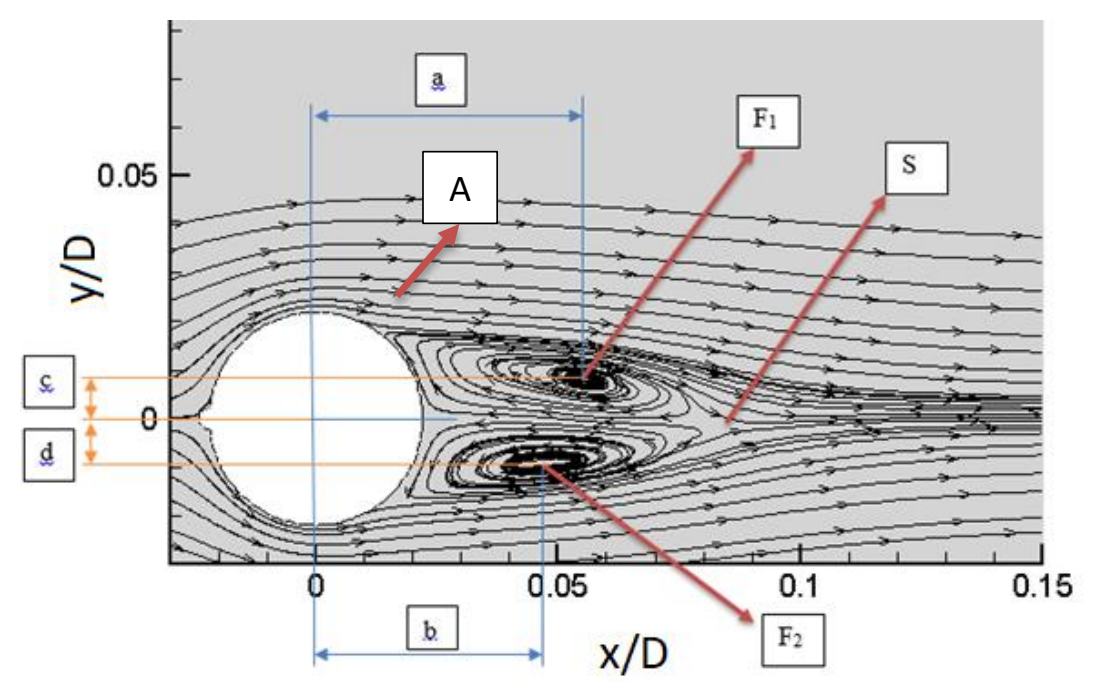

Figure 5. View of received result values

Figure 6 shows the streamlines and TKE contours according to the positions of semi-circular cylinders placed on the cylinder with different position angles. When the figures are examined, it is seen that $F_{1}$ and $\mathrm{F}_{2}$ vortex centers vary for different models. The vortex centres and the separation point positions are given in Table 1. The $\mathrm{X}$-values in $\mathrm{F}_{1}$ and $\mathrm{F}_{2}$ correspond to the values of (a) and (b) and the $\mathrm{Y}$-values correspond to the values of (c) and (d), respectively.

While the vortex points approach the $\mathrm{X}$-axis for the models with $135^{\circ}$ and $180^{\circ}$, these points become distanced from the $\mathrm{X}$-axis for the models with $45^{\circ}$ and $90^{\circ}$ and so the wake area gets larger. When the vortex positions according to the $\mathrm{Y}$ axis were examined, it was observed that models with $0^{\circ}$ and $135^{\circ}$ degrees were the closest models to the axis, and vortex centers farther from the axis occurred at the position of $45^{\circ}, 90^{\circ}$ and $180^{\circ}$ degrees. This leads to streamline for the models with $0^{\circ}$ and $135^{\circ}$ degrees.

When the locations of the saddle points, $\mathrm{S}$ are examined in Table 1 , it is confirmed that the $0^{\circ}$ and $135^{\circ}$ semi-circular protrusion position models are similar and have narrow downstream field than the other models. While this S-point is very close to the $\mathrm{X}$-axis at all angle values, this point is at the most distant point in the Y-axis at $90^{\circ}$. At the same time, the greatest TKE values are seen at $90^{\circ}$ in Fig. 6 because of the maximum values of the vortex forms for the $90^{\circ}$ position model. The growth of the downstream area and the high TKE value cause to increase the vortex movements and thus the frequency values change.

Table 1. The vortex centers and the separation point positions

\begin{tabular}{|c|c|c|c|c|c|c|}
\hline & & $\mathbf{F}_{1}$ & $\mathbf{F}_{2}$ & $\mathbf{S}$ & $\begin{array}{c}\text { Separation } \\
\text { Point }\end{array}$ & $\begin{array}{c}\text { Separation } \\
\text { Angle }\left(^{\circ}\right)\end{array}$ \\
\hline \multirow[t]{2}{*}{$\mathbf{0}^{\circ}$} & $\mathrm{x} / \mathrm{D}$ & 0.054 & 0.045 & 0.082 & 0.0106 & 118,78 \\
\hline & $\mathrm{y} / \mathrm{D}$ & 0.008 & -0.008 & -0.0009 & 0.0193 & \\
\hline \multirow[t]{2}{*}{$45^{\circ}$} & $\mathrm{x} / \mathrm{D}$ & 0.075 & 0.085 & 0.141 & 0.0067 & 107,62 \\
\hline & $\mathrm{y} / \mathrm{D}$ & 0.022 & -0.009 & 0.007 & 0.0211 & \\
\hline \multirow[t]{2}{*}{$90^{\circ}$} & $\mathrm{x} / \mathrm{D}$ & 0.075 & 0.086 & 0.134 & 0.0013 & 93,07 \\
\hline & $\mathrm{y} / \mathrm{D}$ & 0.020 & -0.009 & 0.008 & 0.0242 & \\
\hline \multirow[t]{2}{*}{$135^{\circ}$} & $\mathrm{x} / \mathrm{D}$ & 0.0603 & 0.051 & 0.096 & 0.0114 & 121,10 \\
\hline & $\mathrm{y} / \mathrm{D}$ & 0.0089 & -0.011 & -0.0003 & 0.0189 & \\
\hline \multirow[t]{2}{*}{$180^{\circ}$} & $\mathrm{x} / \mathrm{D}$ & 0.0545 & 0.0534 & 0.1032 & 0.0071 & 108,60 \\
\hline & $\mathrm{y} / \mathrm{D}$ & 0.0110 & -0.0105 & -0.0016 & 0.0211 & \\
\hline
\end{tabular}




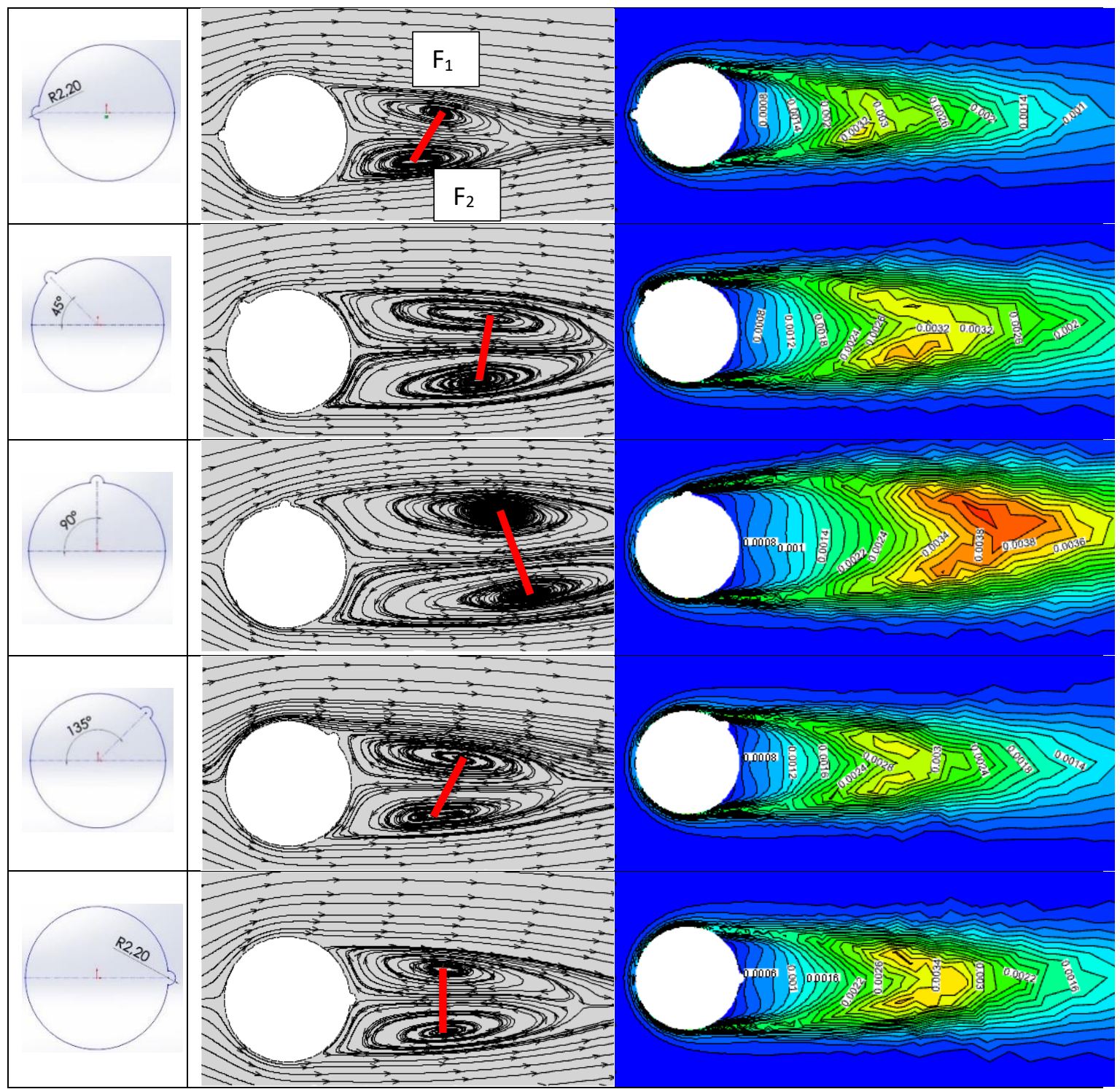

Figure 6. Streamlines and TKE contours of the models

The separation point and angle values are given in Table 1, and also these separation points are shown angularly in Fig. 7. The earliest separation point has occurred at $93,07^{\circ}$ in the model where the protrusion has at $90^{\circ}$ position, while the latest separation point is seen at $121,1^{\circ}$ in the model at $135^{\circ}$ protrusion position. When the separation point angles are examined, the flow separations are close to each other for the models in the $0^{\circ}$ and $135^{\circ}$, and $45^{\circ}$ and $180^{\circ}$ positions, while the model with $90^{\circ}$ position is different from other models and it has an early separation. 


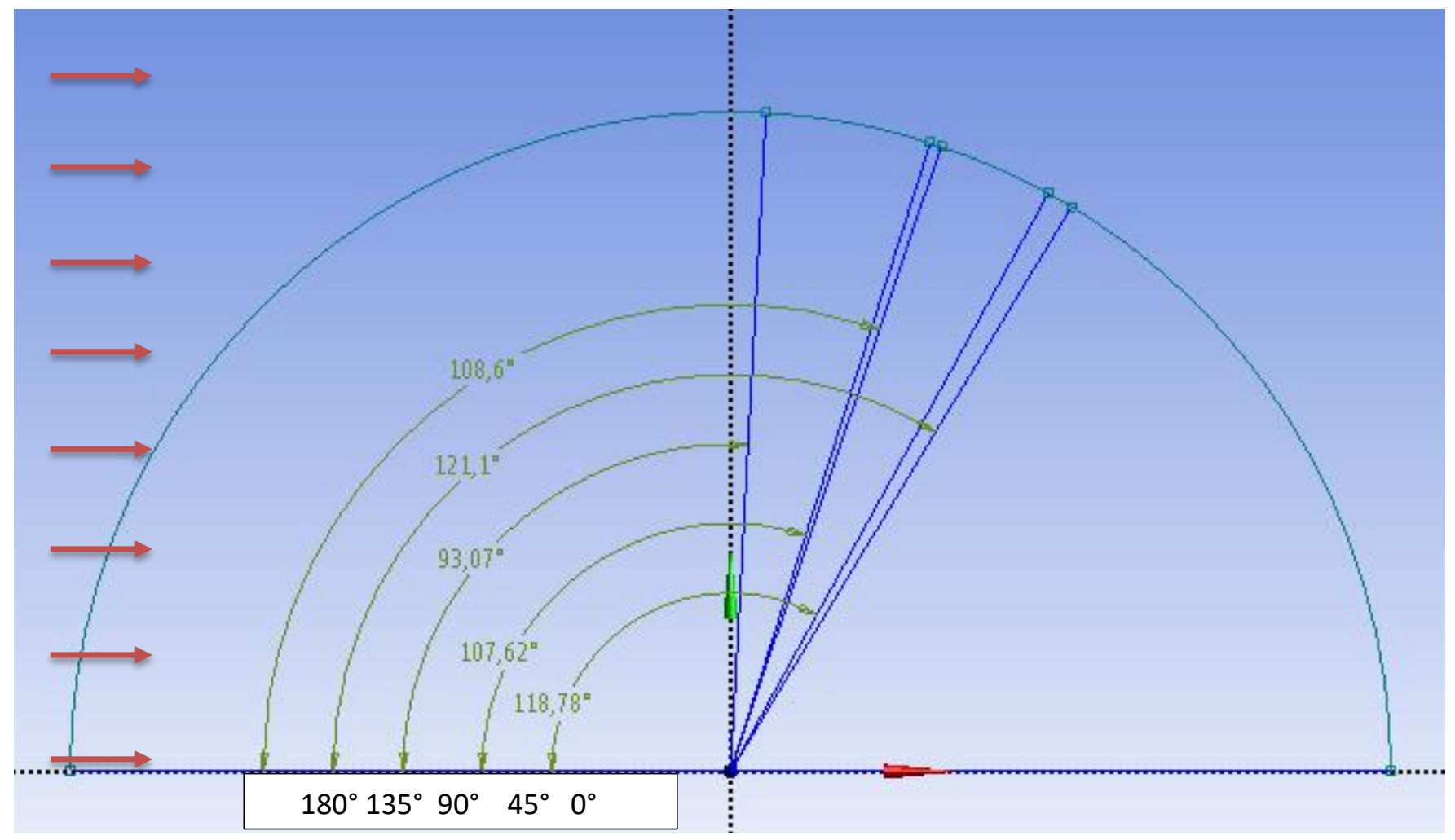

Figure 7. The angular position of separation points

The drag coefficient, $C_{D}$ and pressure drop as a function of the semi-circular protrusion position on the cylinder is given in Fig. 8. The pressure drop and drag coefficient curve are obtained in parallel and in relation to each other. For the $0^{\circ}$ position model, which divides the free flow region symmetrically into two parts, the lowest $C_{D}$ value is obtained due to the lowest pressure drop. These pressure drop and drag coefficient values obtained at the $135^{\circ}$ and $180^{\circ}$ position models are very close to the $0^{\circ}$ position, and highest at $90^{\circ}$ models.

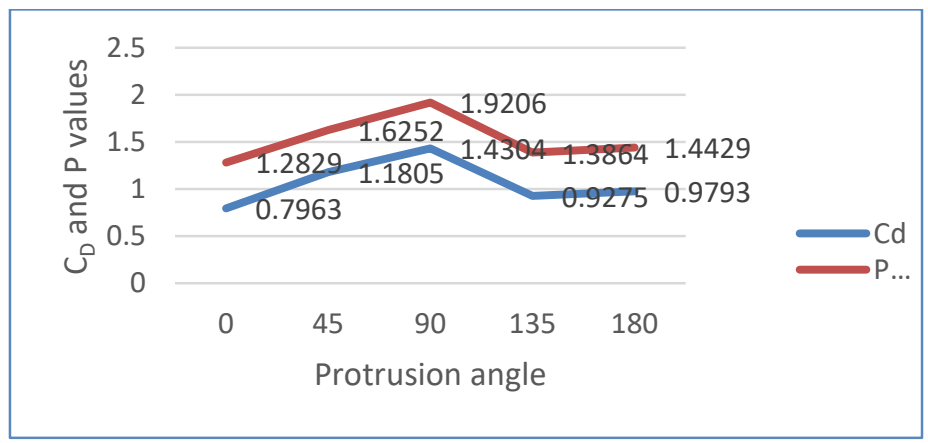

Figure 8. $C_{D}$ drag coefficient and $P$ values versus semi-circular protrusions angles 

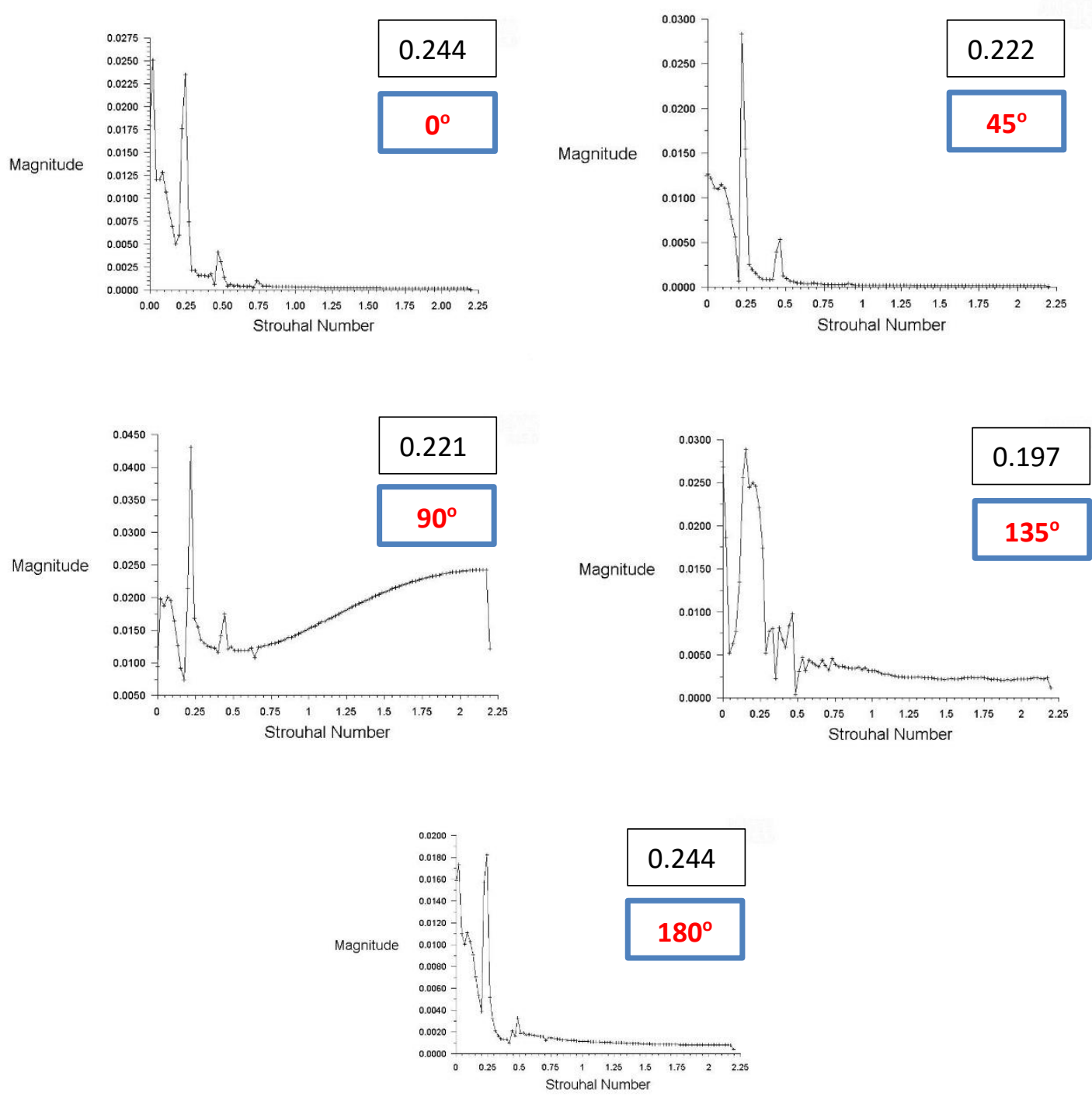

Figure 9. Magnitude versus Strouhal (St) number in different positions

Strouhal number, St formed by the oscillation movements created by the flow is one of the dimensionless numbers depending on the frequency, cylinder diameter, and flow rate. Figure 9 shows the amplitude values connected to the $S t$ numbers at the specific point selected $(x / D=1, y / D=0.5)$ by using timedependent CFD analysis. Accordingly, the lowest St number is seen in the $135^{\circ}$ model. St numbers were obtained to be the same for models with $0^{\circ}$ and $180^{\circ}$ and to be close to $45^{\circ}$ and $90^{\circ}$ models. Minimum vortex frequency, $\mathrm{f}_{\mathrm{s}}$ was occurred for $135^{\circ}$ model, $(1,02 \mathrm{~Hz})$ calcuated with the Equation 6 .

\section{CONCLUSION}

In this study, the effect of the half cylinder with a diameter of $\mathrm{d}=4.4 \mathrm{~mm}(\mathrm{~d} / \mathrm{D}=0.1)$ on the cylinder (D $=44 \mathrm{~mm})$ in the channel at different positions $\left(0^{\circ}, 45^{\circ}, 90^{\circ}, 135^{\circ}\right.$ and $\left.180^{\circ}\right)$ on the flow structure was investigated in $2 \mathrm{D}$. The downstream flow characteristics have been investigated for $\operatorname{Re}_{\mathrm{D}}=10^{4}$ based on free flow rate and the cylinder diameter in the 15D x 30D channel, and then the streamlines and TKE contours are given. The effect of protrusion was investigated by finding vortex centers and $\mathrm{C}_{\mathrm{D}}$ drag 
coefficient. The amplitude of the vortices as depending on St numbers, and the location of the flow separation points from streamline graphics were obtained. According to the obtained value;

The downstream flow structure is influenced by all models, the vortex centers and the streamline points are changed.

- Models with $0^{\circ}$ and $135^{\circ}$ were found to be the closest flow structure.

- For all models, flow separation was shown clockwise at different angles on the X-axis. The early and latest flow separation points were seen in the model with $90^{\circ}$ and $135^{\circ}$ protrusion position, respectively.

- Drag coefficient and the pressure drop were found to be minimum at the models with $0^{\circ}$ and $135^{\circ}$ degrees and to be maximum at the models with $90^{\circ}$.

- The lowest value of the Strouhal number, which is an indicator of the downstream oscillation movement, was obtained to be 0,197 at the model with $135^{\circ}$.

- It was seen that the protrusion on the cylinder placed at different angles changes flow structure and controls the separation.

- In later studies, the different states of the flow control structures can be examined by changing both the size and the shape geometry of the roughness.

\section{ACKNOWLEDGE}

This work is supported by the Scientific Research Project Fund of Sivas Cumhuriyet University under the project number "M-728".

\section{REFERENCES}

[1] Celik S., Karakus C., Akilli H., Sahin B., Investigation of flow structure on finite-cylinder by particle imaging measurement technique (PIV), Installation Engineering, Issue 125 (2011) 33-51

[2] Canpolat C., Sahin B., Influence of single rectangular groove on the flow past a circular cylinder, International Journal of Heat and Fluid Flow 64 (2017) 79-88

[3] Gundemir O., Tastan K., Effects of longitudinal groove-roughness elements on the drag force exerted by the flow on a pipe, J. Fac. Eng. Arch. Gazi Univ. 23 (3) (2008) 637-644

[4] Oguz B., Akar M. A., Pınar E., Akilli H., Sahin B., Control of flow structure in the wake region of circular cylinder with meshy wire in deep water, Pamukkale University Journal of Engineering Sciences, 22(4) (2016) 280-284

[5] Akar M. A., Kucuk M., Control of the unsteady flow structure behind the cylinder with passive control method, Pamukkale University Journal of Engineering Sciences 20 (4) (2014) 123-128

[6] Ranjith E. R., Sunil A. S., Lippin P., Analysis of flow over a circular cylinder fitted with helical strakes, Procedia Technology 24 (2016) 452-460

[7] Yeo D. H., Jones N. P., Computational study on aerodynamic mitigation of wind-induced, largeamplitude vibrations of stay cables with strakes, Journal of Wind Engineering and Industrial Aerodynamics 99 (2011) 389-399

[8] Lam K., Lin Y. F., Zou L., Liu Y., Investigation of turbulent flow past a yawed wavy cylinder, Journal of Fluids and Structures 26 (2010) 1078-1097 